\title{
VALIDITY OF MESOTHELIN IN OCCUPATIONAL MEDICINE PRACTICE
}

\section{PETRA SMOLKOVÁ ${ }^{1}$, MARIE NAKLÁDALOVÁ ${ }^{1}$, JANA ZAPLETALOVÁ ${ }^{2}$ PETR JAKUBEC ${ }^{3}$, HELENA VILDOVÁ ${ }^{1}$, VÍTĚZSLAV KOLEK ${ }^{3}$, MARTIN PETŘEK ${ }^{4}$, and ZDENĚK NAKLÁDAL ${ }^{5}$}

\author{
${ }^{1}$ Palacký University, Olomouc, Czech Republic
}

Faculty of Medicine and Dentistry and University Hospital Olomouc, Department of Occupational Medicine

${ }^{2}$ Palacký University, Olomouc, Czech Republic

Faculty of Medicine and Dentistry, Department of Medical Biophysics

${ }^{3}$ Palacký University, Olomouc, Czech Republic

Faculty of Medicine and Dentistry and University Hospital Olomouc, Department of Respiratory Medicine

${ }^{4}$ Palacký University, Olomouc, Czech Republic

Faculty of Medicine and Dentistry, Department of Pathological Physiology

${ }^{5}$ Regional Public Health Authority of the Olomouc Region, Olomouc, Czech Republic

\begin{abstract}
Objectives: Malignant mesothelioma (MM) is the most serious asbestos-related disease. Its increasing incidence is alarming, suggesting the need for as early diagnosis as possible. This 4.5 -year prospective longitudinal study aimed at assessing the benefit of measuring serum mesothelin as a marker for diagnosing malignant mesothelioma in individuals with previous occupational exposure to asbestos, as a part of their clinical follow-up care. Material and Methods: The study comprised 309 participants (235 males, 74 females) with a mean age of 58.9 years (standard deviation $(\mathrm{SD})=9.8$ ) and a mean duration of exposure to asbestos dust of 13.4 years $(S D=9.3$ ). From 2009 to June 2013, all subjects were followed at a department of occupational medicine in Olomouc. Apart from the standard parts of medical examination (history, physical examination, simple chest radiographs and spirometry), the patients' serum mesothelin levels were determined by the Mesomark immunoenzymatic diagnostic assay. Statistical analysis of the validity of serum mesothelin level measurement was carried out with respect to the diagnosis of MM. Results: Among the participants, 16 (5.2\%) individuals (14 males and 2 females) were diagnosed with malignant mesothelioma. Based on the detected mesothelin levels, their validity for prediction of malignant mesothelioma was calculated as follows: sensitivity -0.75 , specificity -0.962 , positive predictive value -0.706 , negative predictive value -0.969 , positive and negative likelihood ratios -19.95 and 0.26 , respectively, and diagnostic odds ratio - 76.8, at a 95\% confidence interval. Conclusions: The high specificity was identified indicating the low false positivity as well. In the case of detecting elevated soluble mesothelin-related peptides (SMRP) levels in formerly asbestos-exposed individuals, the possibility of the presence of MM should be included into the clinical consideration. The high negative predictive value denotes a lower probability of the presence of MM in patients with normal SMRP levels but due to the limiting lower sensitivity this possibility cannot be entirely excluded.
\end{abstract}

Key words:

Occupational exposure, Asbestos, Malignant mesothelioma, Mesothelin, Diagnostic test, Validity

Financial support by grants titled "Selected aspects of the study of molecular pathogenetic mechanisms of inflammatory diseases and treatment complications" (IGA UP 2015_020), program manager: Prof. Martin Petřek; "Identification of prognostic and predictive factors in non-small cell lung cancer patients treated by adjuvant chemotherapy" (NT/13569-4), program manager: Prof. Vítězslav Kolek; "Selected aspects of the study of molecular mechanisms of inflammatory diseases and transplantations II" (IGA_LF_2014_012), program manager: Prof. Martin Petřek; grants from Palacký University Olomouc(IGA_UP_LF_2014_012; IGA UP 2015_020), grant manager: Prof. Martin Petřek, M.D., C.Sc.; and Czech Ministry of Health (NT/13569-4), grant manager: Prof. Vítězslav Kolek, M.D., Dr.Sc.

Received: March 19, 2015. Accepted: June 12, 2015.

Corresponding author: P. Smolková, Palacký University, Faculty of Medicine and Dentistry and University Hospital Olomouc, Department of Occupational Medicine, I.P. Pavlova 6, 77520 Olomouc, Czech Republic (e-mail: smolkova.p@gmail.com). 


\section{INTRODUCTION}

Occupational exposure to asbestos dust is associated with the potential development of diseases that in the Czech Republic may be recognized as occupational: malignant mesothelioma (MM), pleural hyalinosis, asbestosis, lung cancer, laryngeal cancer and ovarian cancer. Despite the fact that in 2005, the use of asbestos was banned in Europe and most developed countries [1], damage to the health of individuals previously exposed to asbestos still constitutes a global problem as especially MM is characterized by a long clinical latency period of 20-40 years from the time of initial asbestos exposure [2]. Male mortality rates for malignant pleural mesothelioma (MPM) have been rising in most Western European countries [3]. In 2018, approximately 9000 males are estimated to die of MPM (as compared with 5000 in the year 1998) [3]. High incidence rates for MM are reported in the United Kingdom, Belgium and the Netherlands and lower rates in the other Western European countries, with the peak incidence being expected around the year 2020 [3]. High mortality rates were also observed in Australia and New Zealand [4].

Prognostically, MM is the most serious of all asbestos-related diseases. It is a highly malignant, locally aggressive type of cancer involving the pleura, peritoneum or, rarely, pericardium and tunica vaginalis of the testis [5]. There are 3 main histological subtypes of MM: epithelioid (60\%), sarcomatoid (10\%) and biphasic (30\%), with the latter combining features of both the epithelioid and sarcomatoid subtypes [6]. The median survival from the time of diagnosis is 7-9 months [1]. The therapeutic options (chemotherapy and, in some cases, surgery) are still limited [5,7]. Initially, MM spreads along the pleural and peritoneal surfaces with no large masses being present; therefore, it is difficult to diagnose [8]. The clinical symptoms are often nonspecific and may indicate already advanced disease. Typically, there is pleural effusion associated with chest wall pain, dyspnea or cough; at the time of diagnosis, a negative feature is weight loss and fatigue [6]. Therefore, there is a need for a clinically relevant biomarker with the highest diagnostic yield possible. Current options for the diagnosis of this cancer include, among others, measurement of the biomarker mesothelin in serum or pleural fluid.

In 1992, an antibody against mesothelin was 1st isolated [9]. In 2003, Robinson et al. considered mesothelin as a potential biomarker for mesothelioma determined by enzyme-linked immunosorbent assay (ELISA) [10]. The mesothelin precursor is a $69-\mathrm{kDa}$ protein cleaved into a membrane-bound 40$\mathrm{kDa}$ cell surface glycoprotein and a soluble $31-\mathrm{kDa}$ N-terminal fragment referred to as megakaryocyte potentiating factor (MPF) or $\mathrm{NH}_{2}$-terminal-expressed in renal carcinoma (N-ERC)/mesothelin [2,7,11]. Circulating mesothelin is thought to be associated with abnormal splicing events and enzymatic cleavage from membrane-bound mesothelin $[7,12]$. However, the exact mechanisms leading to the release of mesothelin from the membrane are not known. A total of 3 immunological variants of the soluble fraction of the mesothelin gene product have been described [2]. All soluble forms of mesothelin are referred to as soluble mesothelin-related peptides (SMRPs) [2]. In the literature, the term mesothelin has the same meaning as SMRP. In serum or pleural fluid, SMRPs may be determined by immunoenzymatic diagnostic assays, a very common example being Mesomark, as documented in numerous studies [13-16]. Although the role of mesothelin in normal and cancer cells still remains unclear [17], it has been suggested that mesothelin could be a factor promoting tumor invasion [18]. It has been shown that under normal circumstances, mesothelin is present in several human tissues, including the mesothelium and is aberrantly expressed mainly by MM but also by pancreatic cancer, ovarian cancer or some breast and lung cancers [7,12,19]. The drawbacks are that SMRP may be also increased in renal failure or hypertension [13] and the fact that the levels are significantly increased particularly in patients with epithelioid MM [7]. This prospective longitudinal study aimed at assessing the benefit of measuring serum SMRP levels in 
the detection and diagnosis of MM in patients with past occupational exposure to asbestos as a part of their followup and preventive care.

\section{MATERIAL AND METHODS}

\section{Patients and procedures}

The study comprised 309 participants (235 males, 74 females) with a mean age of 58.9 years (standard deviation $(\mathrm{SD})=9.8$ ) and a mean duration of exposure to asbestos dust of 13.4 years $(\mathrm{SD}=9.3$ ). The vast majority of them were employed in 2 asbestos manufacturing plants (processing both chrysotile and crocidolite); only 11 individuals were exposed in other workplaces handling asbestos products (e.g., cutting asbestos boards). From 2009 to June 2013, all subjects received preventive care or were followed after having been diagnosed with diseases caused by exposure to asbestos. Apart from their history, physical examination, simple chest radiographs and basic spirometry were performed and the patients' serum mesothelin levels were measured with the Mesomark immunoenzymatic diagnostic assay. In some patients previously exposed to asbestos, SMRP levels were repeatedly measured; therefore, data from their last follow-up visit were included in the study. In patients with MM, data obtained at the time of diagnosis were analyzed. Individuals with increased mesothelin level $(>1.5 \mathrm{nmol} / \mathrm{l})$ or those with clinical symptoms (dyspnea, cough, chest pain) or even minimal radiographic signs underwent high-resolution computed tomography (HRCT) of the lungs and/or positron emission tomography / computed tomography (PET/CT) scans. The scans were assessed by both radiologists with experience in describing changes caused by fibrogenic dusts and occupational physicians using the International Labour Organization standard classification of radiographs of pneumoconioses [20]. In patients with confirmed pathological findings and suspected of having MM, morphological (histological) examination was carried out to make a definite diagnosis.
The results were statistically processed and validity of serum SMRP level measurement was analyzed with respect to the diagnosis of MM.

\section{Mesothelin (SMRP) measurement}

Serum SMRP levels were detected by ELISA (Mesomark; Fujirebio Diagnostics, USA); the test was performed according to the manufacturer's instructions. Soluble mesothelin-related peptides levels $\leq 1.5 \mathrm{nmol} / \mathrm{l}$ cut-off value were considered normal; those $>1.5 \mathrm{nmol} / \mathrm{l}$ were considered elevated.

\section{Statistics}

The obtained data were analyzed using the IBM SPSS Statistics version 22 software (USA). To predict MM from increased SMRP levels, sensitivity, specificity, positive predictive value (PPV), negative predictive value (NPV), false positivity, false negativity, positive and negative likelihood ratio (LR) and diagnostic odds ratio (DOR) including 95\% confidence intervals (CI) were calculated. The Mann-Whitney U test was used to compare SMRP levels in patients with and without MM.

\section{RESULTS}

Serum SMRP concentrations were studied in 309 patients; of those, $47(15.2 \%)$ had increased levels. The mean serum SMRP level in these patients was $2.74 \mathrm{nmol} / \mathrm{l}$. In a group of $16 \mathrm{MM}$ patients, serum SMRP levels were increased in 12 cases (75\%) with the mean SMRP level $4.06 \mathrm{nmol} / \mathrm{l}$. Among patients with confirmed epithelioid MM, which was the most abundant histologic type, 10 (83.3\%) had elevated SMRP concentrations. In one single case of biphasic mesothelioma, SMRP level was above the cut-off value. Out of the 3 histologically unspecified mesotheliomas, SMRP concentrations were elevated in 2 cases. It was found out that SMRP concentrations among patients with MM were significantly higher $(\mathrm{p}<0.0001$, Mann-Whitney U test) than in the other remaining asbestos-exposed persons. 
Table 1. Characteristics of the group and the prevalence of malignant mesothelioma (MM)

\begin{tabular}{|c|c|}
\hline Variable & $\begin{array}{c}\text { Respondents } \\
(\mathrm{N}=309)\end{array}$ \\
\hline \multicolumn{2}{|l|}{$\operatorname{Sex}[\mathrm{n}(\%)]$} \\
\hline male & $235(76.10)$ \\
\hline female & $74(23.90)$ \\
\hline Age [years] $(\mathrm{M} \pm \mathrm{SD})$ & $58.90 \pm 9.80$ \\
\hline Exposure to asbestos dust [years] $(\mathrm{M} \pm \mathrm{SD})$ & $13.40 \pm 9.30$ \\
\hline MM cases $[\mathrm{n}(\%)]$ & $16(5.20)$ \\
\hline Epithelioid MM [n (\%)] & $12(3.90)$ \\
\hline Latency period of MM [years] $(\mathrm{M} \pm \mathrm{SD})$ & $40.80 \pm 8.90$ \\
\hline \multicolumn{2}{|l|}{ Increased SMRP level } \\
\hline $\operatorname{total}[\mathrm{n}(\%)]$ & $47(15.20)$ \\
\hline serum SMRP level [nmol/1] (M) & 2.74 \\
\hline in $\mathrm{MM}[\mathrm{n}(\%)]$ & $12(75.00)$ \\
\hline serum SMRP level [nmol/l] (M) & 4.06 \\
\hline in epithelioid MM [n (\%)] & $10(83.30)$ \\
\hline in other malignancies [n $(\%)$ ] & $2(0.70)$ \\
\hline
\end{tabular}

$\mathrm{M}$ - mean; SD - standard deviation.

SMRP - soluble mesothelin-related peptide.

The SMRP cut-off value was $1.5 \mathrm{nmol} / \mathrm{l}$.

Soluble mesothelin-related peptides levels were also increased in 2 (out of 3 detected) cases of other malignancies, 1 case each of pancreatic cancer and breast cancer. The basic descriptive characteristics of the subjects, prevalence of MM and the number of individuals with increased SMRP levels in the entire group and in the MM subgroup are shown in Table 1.

The results included the high specificity and NPV and the lower sensitivity of SMRP for MM. Specificity was 0.962 (95\% CI: 0.914-0.988), sensitivity 0.75 (95\% CI: 0.4760.927 ), false negativity 0.25 (95\% CI: $0.073-0.524)$ and false positivity was 0.038 (95\% CI: $0.012-0.086)$.

The high NPV was equal to 0.969 (95\% CI: 0.9240.992). Positive predictive value was lower again: 0.706 (95\% CI: 0.44-0.897). Calculated results of positive and negative likelihood ratios (PLR, NLR) were 19.95 (95\% CI: 8.17-49.33) and 0.26 (95\% CI: 0.11-0.61), respectively, and DOR was 76.8 (95\% CI: 18.2-325).
Table 2. Validity of soluble mesothelin-related peptide (SMRP) levels with respect to malignant mesothelioma (MM)

\begin{tabular}{lc}
\hline \multicolumn{1}{c}{ Parameter } & Validity $(95 \%$ CI $)$ \\
\hline Sensitivity & $0.750(0.476-0.927)$ \\
Specificity & $0.962(0.914-0.988)$ \\
False positivity & $0.038(0.012-0.086)$ \\
False negativity & $0.250(0.073-0.524)$ \\
Positive predictive value & $0.706(0.440-0.897)$ \\
Negative predictive value & $0.969(0.924-0.992)$ \\
Positive likelihood ratio & $19.950(8.170-49.330)$ \\
Negative likelihood ratio & $0.260(0.110-0.610)$ \\
Diagnostic odds ratio & $76.800(18.20-325.00)$ \\
\hline
\end{tabular}

CI - confidence interval.

The validity parameters are presented in Table 2 . It should be added that the participants were also diagnosed with pleural hyalinosis of varying severity (69 cases, 22.3\%; of those, 21 cases met the criteria for 
recognition of the condition as occupational disease), asbestosis ( 4 cases) and lung adenocarcinoma (1 case).

\section{DISCUSSION}

The results of the present study points to the high specificity of the test, which also indicates the low false positivity. Practically, this means that in the case of detecting elevated SMRP levels in formerly asbestos-exposed individuals, the possibility of the presence of MM should be included into the clinical consideration. The high NPV then signifies a high probability of the absence of the disease when the result is negative, but the prevalence in the population tested limits the diagnostic value of this result. Sensitivity of the test is lower and associated with the large confidence interval. This is caused by the low number of patients with MM.

The high PLR means almost the 20 times higher probability of being SMRP-positive in relation to the presence of MM. The result of NLR indicates that the probability of suffering from MM when the test was negative was $26 \%$ and high DOR would represent a useful diagnostic test. However, the added diagnostic value of these parameters including sensitivity, false negativity and PPV is markedly attenuated owing to the considerably large confidence intervals whose estimation was strongly influenced by the low number of patients with MM in our test group.

Despite minor differences in the findings of studies performed in populations with occupational exposure to asbestos, the use of SMRP concentrations in the detection and diagnosis of MM seems quite beneficial. An Italian study by Filiberti et al. comprising approximately 1700 persons exposed to asbestos displayed a rather reluctant attitude of the authors towards the use of SMRP levels as a screening marker for MM, who stated that other clinical and demographic factors must be considered such as age, smoking status, a positive history of cancer and others [21]; this is consistent with some other studies of asbestos-exposed persons [22,23]. The ability of SMRP concentrations to predict the development of MM in advance has so far been quite debatable and more or less supported by single cases [24]. Based on the results of their study, Filiberti et al. do not support this ability for a time interval of 1 year [25], while Rodríguez Portal et al. concluded that serum SMRP levels could serve as a marker of exposure to asbestos [26].

In a 2010 meta-analysis by Luo et al., the sensitivity of SMRP with respect to MM was determined at 0.64 , specificity at 0.89 , positive LR at 7.1, negative LR at 0.39 and diagnostic OR at 19.35 [14]. However, the authors have claimed that serum SMRP determination plays a role in the diagnosis of MM and SMRP concentrations should be interpreted in parallel with clinical findings and results of conventional tests. In their 2014 updated metaanalysis, Cui et al. were less positive about the accuracy of SMRP measurements in serum and pleural fluid for diagnosing MPM [7]. After careful selection, 30 studies were included in the meta-analysis. The pooled sensitivity of serum SMRP measurements was 0.61 , specificity 0.87 , positive LR 5.71, negative LR 0.43 and DOR 14.43. Cui et al. [7] have concluded that both serum and pleural fluid SMRP levels are helpful markers for the diagnosis of MPM. As shown above, the usefulness of SMRP concentration measurements for diagnosing MM was better in the present study than in the latest meta-analysis [7]. However, the difference is not significant given the large confidence intervals (in particular for sensitivity, PPV, positive LR and DOR, as it has been already discussed), mainly due to the low number of MM cases in the present study.

Numerous other studies have confirmed the diagnostic yield and convenience of the use of SMRP concentrations for the diagnosis of $\mathrm{MM}$, often recommending consideration of further diagnostic steps in case of positive results [5,13,27-30]. For instance, in a recent review, Cristaudo et al. have stated that SMRP levels seem to be the most adequate biomarker for MM in spite of the fact that they may be genetically and clinically affected [2]. 
Given the generally lower limiting sensitivity of SMRP levels, other possibilities combining SMRPs and other markers continue to be investigated. According to some authors, combinations of several markers could increase the diagnostic accuracy [2,31,32]; however, this hypothesis is not supported by all studies [30]. Thus, numerous markers have already been tested in this context, mostly megakaryocyte-potentiating factor (MPF), usually considered a component of the soluble fraction of mesothelin (see above) and osteopontin [2,11,30,31,33-38]. The highest yield seems to be associated with MPF determination. According to Cui et al., the diagnostic accuracy of serum MPF concentrations was even higher than that of SMRP levels [7]. Some authors even suggest that MPF can be used interchangeably with SMRP $[2,33]$. This conclusion is supported by a large Japanese study by Hirohashi et al. who determined N-ERC/mesothelin or MPF levels in 40000 asbestos-exposed participants. These were shown to be a potentially useful blood tumor markers for the early diagnosis of MM in asbestos-exposed populations, even in case of mass examination [38]. Although osteopontin alone showed insufficient specificity [2], some studies support the utility of SMRP levels combined with osteopontin concentrations [11,31]. Other investigated markers included, for instance, CYFRA 21-1 (cytokeratin 19-fragments), cancer antigen 15.3 (CA), CA 125 (MUC 16), calretinin, carcinoembryonic antigen, intelectin-1, human mammoglobin, tissue polypeptide antigen, VEGF (vascular endothelial growth factor), EMA (endomysial antibody), Ber-Ep4 (mouse monoclonal EpCAM antibody), TTF-1 (thyroid transcription factor-1) or hyaluronic acid [30,31,39-42]. So-called pleural fluid DNA integrity index is another candidate biomarker for diagnosing malignant pleural effusions, including mesothelioma [43].

A very promising approach in the nearest future seems to be determination of SMRP levels as a part of treatment response monitoring or even prognosis estimates [7,28,32,37,44,45]. Grigoriu et al. reported that while increasing serum SMRP levels were associated with disease progression and worse outcome, stable or decreasing concentrations suggested response to treatment [44]. According to Cristaudo et al., high SMRP levels could be considered an independent negative prognostic factor in patients with MM [28].

Another remarkable option that has been at the forefront of investigators' interest in recent years is the therapeutic use of mesothelin in the form of mesothelin-targeted immunotherapies. For these purposes, the use of recombinant immunotoxins, monoclonal antibodies and T-cell therapy has been studied, all in potential combination with chemotherapy, as well as of antimesothelin vaccines or antibody-conjugates [46-49]. Most recently, gene-based targeted therapy considering mesothelin a key molecular target has been suggested [17].

Generally, it may be concluded that more recent studies suggest the use of SMRP levels as a suitable marker in association with the effectiveness of MM therapy and investigate the potential for further improvement of the diagnostic accuracy of SMRP levels by combining them with other markers. A very important area of recent research is mesothelin-targeted immunotherapy.

\section{CONCLUSIONS}

Given the risks associated with former occupational exposure to asbestos, careful preventive care is of crucial importance. The use of adequate examination methods considerably increases the probability of disease detection. In the present study, the high specificity of the test was identified indicating the low false positivity as well. Practically, this means that in the case of detecting elevated SMRP levels in formerly asbestos-exposed individuals, the possibility of the presence of MM should be included into the clinical consideration. The high NPV denotes a lower probability of the presence of MM in patients with normal SMRP levels but due to the limiting 
lower sensitivity, this possibility cannot be entirely excluded. The use of serum SMRP level measurements in the care for previously asbestos-exposed persons appears to be a beneficial supportive diagnostic tool when combined with other diagnostic, in particular imaging, methods.

\section{REFERENCES}

1. Scherpereel A, Astoul P, Baas P, Berghmans T, Clayson $\mathrm{H}$, de Vuyst $\mathrm{P}$, et al. Guidelines of the European Respiratory Society and the European Society of Thoracic Surgeons for the management of malignant pleural mesothelioma. Eur Respir J. 2010;35:479-95, http://dx.doi. org/10.1183/09031936.00063109.

2. Cristaudo A, Bonotti A, Simonini S, Bruno R, Foddis R. Soluble markers for diagnosis of malignant pleural mesothelioma. Biomark Med. 2011;5(2):261-73, http://dx.doi.org/10.2217/ bmm.11.18.

3. Van Meerbeeck JP, Gaafar R, Manegold C, van Klaveren RJ, van Marck EA, Vincent M, et al. Randomized phase III study of cisplatin with or without raltitrexed in patients with malignant pleural mesothelioma: An intergroup study of the European Organisation for Research and Treatment of Cancer Lung Cancer Group and the National Cancer Institute of Canada. J Clin Oncol. 2005;23(28):6881-9, http://dx.doi. org/10.1200/JCO.20005.14.589.

4. Nishikawa K, Takahashi K, Karjalainen A, Wen C-P, Furuya $S$, Hoshuyama $T$, et al. Recent mortality from pleural mesothelioma, historical patterns of asbestos use, and adoption of bans: A global assessment. Environ Health Perspect. 2008;116(12):1675-80, http://dx.doi.org/10.1289/ehp.11272.

5. Hollevoet K, Reitsma JB, Creaney J, Grigoriu BD, Robinson BW, Scherpereel A, et al. Serum mesothelin for diagnosing malignant pleural mesothelioma: An individual patient data meta-analysis. J Clin Oncol. 2012;30(13):1541-9, http:// dx.doi.org/10.1200/JCO.2011.39.6671.

6. Robinson BWS, Musk AW, Lake RA. Malignant mesothelioma. Lancet. 2005;366:397-408.
7. Cui A, Jin X-G, Zhai K, Tong Z-H, Shi H-Z. Diagnostic values of soluble mesothelin-related peptides for malignant pleural mesothelioma: Updated meta-analysis. BMJ Open. 2014;4:1-9, http://dx.doi.org/10.1136/bmjopen-2013-004145.

8. Shiomi K, Hagiwara Y, Sonoue K, Segawa T, Miyashita K, Maeda M, et al. Sensitive and specific new enzyme-linked immunosorbent assay for $\mathrm{N}-\mathrm{ERC} /$ mesothelin increases its potential as a useful serum tumor marker for mesothelioma. Clin Cancer Res. 2008;14(5):1431-7, http://dx.doi. org/10.1158/1078-0432.CCR-07-1613.

9. Chang K, Pastan I, Willingham MC. Isolation and characterization of a monoclonal antibody, K1, reactive with ovarian cancers and normal mesothelium. Int J Cancer. 1992;50(3):373-81.

10. Robinson BWS, Creaney J, Lake R, Nowak A, Musk AW, de Klerk N, et al. Mesothelin-family proteins and diagnosis of mesothelioma. Lancet. 2003;362:1612-6.

11. Bayram M, Dongel I, Akbas A, Benli I, Akkoyunlu ME, Bakan ND. Serum biomarkers in patients with mesothelioma and pleural plaques and healthy subjects exposed to naturally occurring asbestos. Lung. 2014;192:197-203, http:// dx.doi.org/10.1007/s00408-013-9526-9.

12. Sapede C, Gauvrit A, Barbieux I, Padieu M, Cellerin L, Sagan C, et al. Aberrant splicing and protease involvement in mesothelin release from epithelioid mesothelioma cells. Cancer Sci. 2008;99(3):590-4, http://dx.doi.org/10.1111/ j.1349-7006.2007.00715.x.

13. Beyer HL, Geschwindt RD, Glover CL, Tran L, Hellstrom I, Hellstrom K-E, et al. MESOMARK ${ }^{\mathrm{TM}}$ : A potential test for malignant pleural mesothelioma. Clin Chem. 2007;53(4): 666-72, http://dx.doi.org/10.1373/clinchem.2006.079327.

14. Luo L, Shi H-Z, Liang Q-L, Jiang J, Qin S-M, Deng J-M. Diagnostic value of soluble mesothelin-related peptides for malignant mesothelioma: A meta-analysis. Respir Med. 2010;104:149-56, http://dx.doi.org/10.1016/j.rmed.2009.05.017.

15. Maeda M, Hino O. Molecular tumor markers for asbestosrelated mesothelioma: Serum diagnostic markers. Pathol 
Int. 2006;56:649-54, http://dx.doi.org/10.1111/j.1440-1827. 2006.02024.x.

16. Scherpereel A, Grigoriu B, Conti M, Gey T, Grégoire M, Copin $\mathrm{M}-\mathrm{C}$, et al. Soluble mesothelin-related peptides in the diagnosis of malignant pleural mesothelioma. Am J Respir Crit Care Med. 2006;173:1155-60, http://dx.doi.org/10.1164/ rccm.200511-17890C.

17. Melaiu O, Stebbing J, Lombardo Y, Bracci E, Uehara N, Bonotti A, et al. MSLN gene silencing has an anti-malignant effect on cell lines overexpressing mesothelin deriving from malignant pleural mesothelioma. PLoS One. 2014;9(1): e85935, http://dx.doi.org/10.1371/journal.pone.0085935.

18. Servais EL, Colovos C, Rodriguez L, Bograd AJ, Nitadori J, Sima C, et al. Mesothelin overexpression promotes mesothelioma cell invasion and MMP-9 secretion in an orthotopic mouse model and in epithelioid pleural mesothelioma patients. Clin Cancer Res. 2012;18(9):2478-89, http://dx.doi. org/10.1158/1078-0432.CCR-11-2614.

19. Scherpereel A, Lee YCG. Biomarkers for mesothelioma. Curr Opin Pulm Med. 2007;13(4):339-43, http://dx.doi. org/10.1097/MCP.0b013e32812144bb.

20. International Labour Office. Guidelines for the use of the ILO International Classification of Radiographs of Pneumoconioses. Revised edition 2011. Geneva: The Office; 2011. 48 p.

21. Filiberti R, Marroni P, Mencoboni M, Mortara V, Caruso $\mathrm{P}$, Cioé $\mathrm{A}$, et al. Individual predictors of increased serum mesothelin in asbestos-exposed workers. Med Oncol. 2013;30(422):1-8, http://dx.doi.org/10.1007/s12032-0120422-6.

22. Hollevoet K, van Cleemput J, Thimpot J, de Vuyst P, Bosquée L, Nackaerts K. Serial measurements of mesothelioma serum biomarkers in asbestos-exposed individuals. A prospective longitudinal cohort study. J Thorac Oncol. 2011;6(5):889-95, http://dx.doi.org/10.1097/JTO.0b013e318 $20 \mathrm{db} 377$.

23. Park EK, Thomas PS, Creaney J, Johnson AR, Robinson BW, Yates DH. Factors affecting soluble mesothelin related protein levels in an asbestos-exposed population. Clin Chem Lab Med. 2010;48(6):869-74, http://dx.doi. org/10.1515/CCLM.2010.165.

24. Felten MK, Khatab K, Knoll L, Schettgen T, Müller-Berndorff $\mathrm{H}$, Kraus T. Changes of mesothelin and osteopontin levels over time in formerly asbestos-exposed power industry workers. Int Arch Occup Environ Health. 2014;87:195-204, http://dx.doi.org/10.1007/s00420-013-0853-1.

25. Filiberti R, Marroni P, Spigno F, Merlo DF, Mortara V, Caruso $\mathrm{P}$, et al. Is soluble mesothelin-related protein an upfront predictive marker of pleural mesothelioma? A prospective study on Italian workers exposed to asbestos. Oncology. 2014;86:33-43, http://dx.doi.org/10.1159/000355687.

26. Rodríguez Portal JA, Rodríguez Becerra E, Rodríguez Rodríguez D, Alfageme Michavila I, Quero Martínez A, Diego Roza C, et al. Serum levels of soluble mesothelin-related peptides in malignant and nonmalignant asbestos-related pleural disease: Relation with past asbestos exposure. Cancer Epidemiol Biomarkers Prev. 2009;18(2):646-50, http:// dx.doi.org/10.1158/1055-9965.EPI-08-0422.

27. Jakubec P, Pelclova D, Smolkova P, Kolek V, Nakladalova M. Significance of serum mesothelin in an asbestos-exposed population in the Czech Republic. Biomed Pap Med Fac Univ Palacky Olomouc Czech Repub. 2015;159(3):472-9, http://dx.doi.org/10.5507/bp.2014.015.

28. Cristaudo A, Foddis R, Vivaldi A, Guglielmi G, Dipalma N, Filiberti R, et al. Clinical significance of serum mesothelin in patients with mesothelioma and lung cancer. Clin Cancer Res. 2007;13(17):5076-81, http://dx.doi.org/10.1158/10780432.CCR-07-0629.

29. Dipalma N, Luisi V, di Serio F, Fontana A, Maggiolini P, Licchelli $\mathrm{B}$, et al. Biomarkers in malignant mesothelioma: Diagnostic and prognostic role of soluble mesothelin-related peptide. Int J Biol Markers. 2011;26(3):160-5, http://dx. doi.org/10.5301/JBM.2011.8614.

30. Creaney J, Yeoman D, Musk AW, de Klerk N, Skates SJ, Robinson BWS. Plasma versus serum levels of osteopontin and mesothelin in patients with malignant 
mesothelioma - Which is best? Lung Cancer. 2011;74:55-60, http://dx.doi.org/10.1016/j.lungcan.2011.02.007.

31. Cristaudo A, Bonotti A, Simonini S, Vivaldi A, Guglielmi G, Ambrosino N, et al. Combined serum mesothelin and plasma osteopontin measurements in malignant pleural mesothelioma. J Thorac Oncol. 2011;6(9):1587-93, http://dx.doi. org/10.1097/JTO.0b013e31821e1c08.

32. Pantazopoulos I, Boura P, Xanthos T, Syrigos K. Effectiveness of mesothelin family proteins and osteopontin for malignant mesothelioma. Eur Respir J. 2013;41(3):706-15, http://dx.doi.org/10.1183/09031936.00226111.

33. Creaney J, Sneddon S, Dick IM, Dare H, Boudville N, Musk AW, et al. Comparison of the diagnostic accuracy of the MSLN gene products, mesothelin and megakaryocyte potentiating factor, as biomarkers for mesothelioma in pleural effusions and serum. Dis Markers. 2013;35:119-27, http://dx.doi.org/10.1155/2013/874212.

34. Onda M, Nagata S, Ho M, Bera TK, Hassan R, Alexander RH, et al. Megakaryocyte potentiation factor cleaved from mesothelin precursor is a useful tumor marker in the serum of patients with mesothelioma. Clin Cancer Res. 2006;12(14):4225-31.

35. Iwahori K, Osaki T, Serada S, Fujimoto M, Suzuki H, Kishi Y, et al. Megakaryocyte potentiating factor as a tumor marker of malignant pleural mesothelioma: Evaluation in comparison with mesothelin. Lung Cancer. 2008;62:45-54, http://dx.doi.org/10.1016/j.lungcan.2008.02.012.

36. Hollevoet K, Nackaerts K, Thimpont J, Germonpré P, Bosquée L, de Vuyst P, et al. Diagnostic performance of soluble mesothelin and megakaryocyte potentiating factor in mesothelioma. Am J Respir Crit Care Med. 2010;181:620-5, http://dx.doi.org/10.1164/rccm.200907-1020OC.

37. Wheatley-Price P, Yang B, Patsios D, Patel D, Ma C, $\mathrm{Xu} \mathrm{W}$, et al. Soluble mesothelin-related peptide and osteopontin as markers of response in malignant mesothelioma. J Clin Oncol. 2010;28(20):3316-22, http://dx.doi.org/10.12 00/JCO.2009.26.9944.

38. Hirohashi T, Igarashi K, Abe M, Maeda M, Hino O. Retrospective analysis of large-scale research screening of construction workers for the early diagnosis of mesothelioma. Mol Clin Oncol. 2014;2:26-30, http://dx.doi.org/10.3892/ mco.2013.197.

39. Creaney J, van Bruggen I, Hof M, Segal A, Musk AW, de Klerk N, et al. Combined CA125 and mesothelin levels for the diagnosis of malignant mesothelioma. Chest. 2007;132(4):1239-46, http://dx.doi.org/10.1378/chest.07-0013.

40. Van den Heuvel MM, Korse CM, Bonfrer JMG, Baas P. Non-invasive diagnosis of pleural malignancies: The role of tumour markers. Lung Cancer. 2008;59:350-4, http://dx.doi. org/10.1016/j.lungcan.2007.08.030.

41. Filiberti R, Parodi S, Libener R, Ivaldi GP, Canessa PA, Ugolini D, et al. Diagnostic value of mesothelin in pleural fluids: Comparison with CYFRA 21-1 and CEA. Med Oncol. 2013;30(2):543, http://dx.doi.org/10.1007/s12032-013-0543-6.

42. Van der Bij S, Schaake E, Koffijberg H, Burgers JA, de Mol BAJM, Moons KGM. Markers for the non-invasive diagnosis of mesothelioma: A systematic review. Br J Cancer. 2011;104:1325-33, http://dx.doi.org/10.1038/ bjc.2011.104.

43. Sriram KB, Relan V, Clarke BE, Duhig EE, Windsor MN, Matar KS, et al. Pleural fluid cell-free DNA integrity index to identify cytologically negative malignant pleural effusions including mesotheliomas. BMC Cancer. 2012;12:428, http:/ dx.doi.org/10.1186/1471-2407-12-428.

44. Grigoriu B, Chahine B, Vachani A, Gey T, Conti M, Sterman $\mathrm{DH}$, et al. Kinetics of soluble mesothelin in patients with malignant pleural mesothelioma during treatment. Am J Respir Crit Care Med. 2009;179:950-4, http://dx.doi. org/10.1164/rccm.200807-1125OC.

45. Schneider J, Hoffmann H, Dienemann H, Herth FJF, Meister M, Muley T. Diagnostic and prognostic value of soluble mesothelin-related proteins in patients with malignant pleural mesothelioma in comparison with benign asbestosis and lung cancer. J Thorac Oncol. 2008;3:1317-24, http://dx.doi. org/10.1097/JTO.0b013e318187491c.

46. Villena-Vargas J, Adusumilli PS. Mesothelin-targeted immunotherapies for malignant pleural mesothelioma. Ann 
Cardiothorac Surg. 2012;1(4):466-71, http://dx.doi.org/10. 3978/j.issn.2225-319X.2012.10.03.

47. Thomas A, Hassan R. Immunotherapies for non-small-cell lung cancer and mesothelioma. Lancet Oncol. 2012;13:e30110, http://dx.doi.org/10.1016/S1470-2045(12)70126-2.

48. Le DT, Brockstedt DG, Nir-Paz R, Hampl J, Mathur S, Nemunaitis J, et al. A live-attenuated listeria vaccine (ANZ-100) and a live-attenuated listeria vaccine expressing mesothelin
(CRS-207) for advanced cancers: Phase 1 studies of safety and immune induction. Clin Cancer Res. 2012;18(3):858-68, http://dx.doi.org/10.1158/1078-0432.CCR-11-2121.

49. Hassan R, Miller AC, Sharon E, Thomas A, Reynolds JC, Ling $\mathrm{A}$, et al. Major cancer regressions in mesothelioma after treatment with an anti-mesothelin immunotoxin and immune suppression. Sci Transl Med. 2013;5(208):208ra147, http://dx.doi.org/10.1126/scitranslmed.3006941.

This work is available in Open Access model and licensed under a Creative Commons Attribution-NonCommercial 3.0 Poland License - http://creativecommons.org/ licenses/by-nc/3.0/pl/deed.en. 